\title{
R. Tattersall. Diabetes: the biography. Oxford University Press, Oxford, 2009
}

\author{
256pp (ISBN 978019954136 2). Hardcover $£ 12.99$
}

\section{Jörgens}

Received: 18 December 2009/Accepted: 22 December 2009/Published online: 2 February 2010

(C) Springer-Verlag 2010

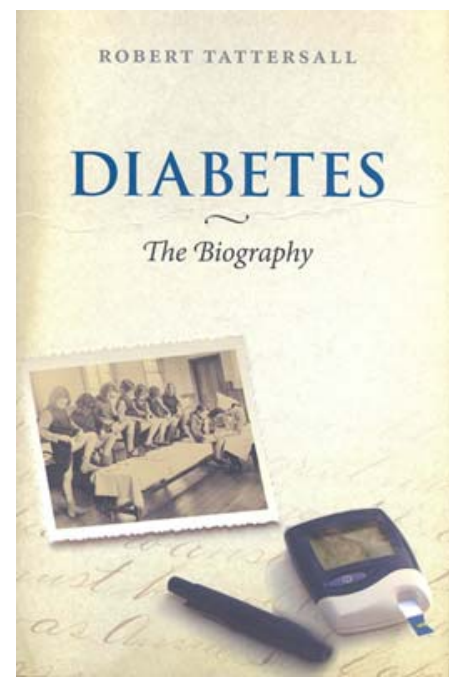

It was a pleasure to read Diabetes: the biography. Robert Tattersall has been working for many years, as he mentions in the preface, on a definitive and exhaustive history of diabetes, and the academic world of diabetes has been looking forward to his magnum opus. He has now published a biography of diabetes with a minimum of references for a wide general readership. Nevertheless, the book is very interesting to read, not only for so-called lay persons, but also for diabetes specialists, as Robert Tattersall addresses many issues and tells many stories that

\section{Jörgens $(\bowtie)$}

EASD/EFSD,

Rheindorfer Weg 3,

40591 Düsseldorf, Germany

e-mail: viktorjoergens@easd.org are not mentioned in the sometimes boring academic books and articles on the history of diabetes.

Rarely has the history of the discovery of insulin been summarised in such a balanced way. Tattersall also points out the major contributions of Macleod and the biochemist Collip to this discovery. There are many historical books on diabetes, but what makes Tattersall's book outstanding is his detailed discussion of the more recent history of diabetes research and care. Who knows that metformin was developed from Galega officinalis? All the ups and downs of di- and biguanides and sulfonylureas over the decades are described in detail. The design and outcome of the University Group Diabetes Programme, which was the first endpoint trial on diabetes treatment, are critiqued. It is particularly interesting to read the chapter on selfmonitoring of blood glucose, since the author himself was one of the first to introduce monitoring and thus actively involve the person with diabetes in his or her treatment. Nor does he forget to mention the story of Richard K. Bernstein, who noticed the importance of blood glucose monitoring in treating his own diabetes, while the company that invented Dextrostix in 1964 missed the opportunity to gain a world market, being exclusively focused on physicians. Another very interesting chapter is the debate that went on for decades on the question of whether good metabolic control prevents complications, which was finally resolved by the DCCT and UK Prospective Diabetes Study (UKPDS).

Because Robert Tattersall has such a profound knowledge of the history of diabetes, it is very difficult to find a mistake in the book; even the contributions of German diabetologists, such as Professor Stolte from Breslau, who instigated 'dose adjustment for normal eating', are reported correctly. However, it is debatable as to who introduced the insulin pump. Tattersall mentions only $\mathrm{H}$. 
Keen and J. Pickup. Based upon personal reports, I think it was H. Keen and K. G. M. M. Alberti who initiated the use of the Mill Hill pump for subcutaneous insulin treatment, although the young doctor Pickup later devoted his career to this idea. Only the name of Paul Kimmelstiel is misspelt; he was born in Hamburg, emigrated in 1933 to the USA where he met Clifford Wilson and published a famous paper on diabetic nephropathy. The obituary for Paul Kimmelstiel by Philippe M. Leconte in Diabetes in 1971 [1] ends with the sentence 'Seldom has anyone been so severely afflicted with the libido sciendi'. Tattersall's book should be offered to young diabetologists: it would certainly increase their 'libido sciendi' and widen their critical view on clinical diabetes research.

\section{Reference}

1. LeCompte PM (1971) Paul Kimmelstiel: an appreciation. Diabetes 20:117-118 